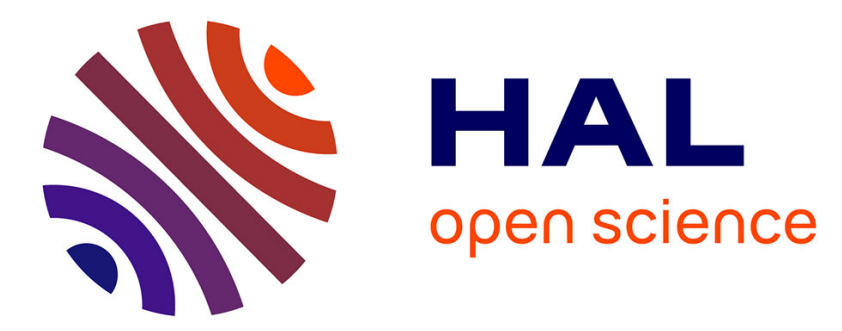

\title{
Rho family GTPases control entry of Shigella flexneri into epithelial cells but not intracellular motility.
}

Joëlle Mounier, Valérie Laurent, A Hall, Philippe Fort, Marie-France Carlier, Philippe Sansonetti, Coumaran Egile

\section{- To cite this version:}

Joëlle Mounier, Valérie Laurent, A Hall, Philippe Fort, Marie-France Carlier, et al.. Rho family GTPases control entry of Shigella flexneri into epithelial cells but not intracellular motility.. Journal of Cell Science, 1999, 112 ( Pt 13), pp.2069-80. hal-02267489

\section{HAL Id: hal-02267489 \\ https://hal.science/hal-02267489}

Submitted on 26 Jun 2020

HAL is a multi-disciplinary open access archive for the deposit and dissemination of scientific research documents, whether they are published or not. The documents may come from teaching and research institutions in France or abroad, or from public or private research centers.
L'archive ouverte pluridisciplinaire HAL, est destinée au dépôt et à la diffusion de documents scientifiques de niveau recherche, publiés ou non, émanant des établissements d'enseignement et de recherche français ou étrangers, des laboratoires publics ou privés.

\section{(c) (1) $\$$}

Distributed under a Creative Commons Attribution - NonCommerciall 4.0 International 


\title{
Rho family GTPases control entry of Shigella flexneri into epithelial cells but
}

\section{not intracellular motility}

\author{
Joëlle Mounier ${ }^{1}$, Valérie Laurent ${ }^{2}$, Alan Hall ${ }^{3}$, Philippe Fort ${ }^{4}$, Marie-France Carlier ${ }^{2}$, Philippe J. Sansonetti ${ }^{1}$ \\ and Coumaran Egile ${ }^{1, *}$
}

\author{
1 Unité de Pathogénie Microbienne Moléculaire, INSERM U 389, Institut Pasteur, 28 rue du Docteur Roux, 75724 Paris Cédex 15, \\ France \\ 2Dynamique du Cytosquelette, Laboratoire d'Enzymologie et Biochimie Structurale, CNRS, UPRA9063, 91198 Gif sur Yvette, France \\ ${ }^{3}$ Medical Research Council Laboratory for Molecular Cell Biology and Department of Biochemistry, University College London, \\ Gower Street, London, WC1E 6BT, UK \\ ${ }^{4}$ CRBM, CNRS-UPR 1086, Route de Mende, 34293 Montpellier Cedex 05, France \\ *Author for correspondence (e-mail: marcou@pasteur.fr)
}

Accepted 13 April; published on WWW 10 June 1999

\section{SUMMARY}

Shigella flexneri, an invasive bacterial pathogen, promotes formation of two cytoskeletal structures: the entry focus that mediates bacterial uptake into epithelial cells and the actin-comet tail that enables the bacteria to spread intracellularly. During the entry step, secretion of bacterial invasins causes a massive burst of subcortical actin polymerization leading the formation of localised membrane projections. Fusion of these membrane ruffles leads to bacterial internalization. Inside the cytoplasm, polar expression of the IcsA protein on the bacterial surface allows polymerization of actin filaments and their organization into an actin-comet tail leading to bacterial spread. The Rho family of small GTPases plays an essential role in the organization and regulation of cellular cytoskeletal structures (i.e. filopodia, lamellipodia, adherence plaques and intercellular junctions). We show here that induction of Shigella entry foci is controlled by the Cdc42, Rac and Rho GTPases, but not by RhoG. In contrast, actin-driven intracellular motility of Shigella does not require Rho GTPases. Therefore, Shigella appears to manipulate the epithelial cell cytoskeleton both by Rho GTPase-dependent and -independent processes.

Key words: Shigella, Epithelial cell, Entry, Actin-based motility, Actin polymerization, Rho GTPase

\section{INTRODUCTION}

Shigella flexneri, a Gram-negative enteric bacteria, is the agent of human bacillary dysentery. This disease is caused by invasion of the colonic mucosa by the microorganism and induction of an intense inflammatory process leading to tissue destruction (Labrec et al., 1964). The pathogenicity of Shigella is largely due to its ability to invade epithelial cells. Cellular invasion by Shigella requires massive rearrangements of the host actin cytoskeleton. Cytoskeletal rearrangements occuring during Shigella invasion have been described in detail in cultured epithelial cells. At the initial stage of contact with host cells, bacteria induce foci of actin polymerization underneath the cell membrane, formation of actin filament bundles and membrane projections. These projections extend in the space surrounding the pathogen and closure above the bacterial body leads to its engulfment by a macropinocytic process (Clerc and Sansonetti, 1987; Adam et al., 1995). Within minutes after entry, Shigella lyses the vacuole, escapes into the cytosol and assembles actin-based machinery to spread inside the cytoplasm (Bernardini et al., 1989). Intracellular bacteria induce localised polymerization of actin filaments and the formation of an actin comet at one pole of the bacterium. Continuous polymerization provides the motile force allowing bacterial motility (Theriot et al., 1992). Spreading bacteria interact with host cell junction components and induce membrane protrusions containing the moving bacteria. After phagocytosis by adjacent cells, these protrusions release bacteria into the new cell, allowing initiation of a new cycle of infection (Sansonetti et al., 1994).

Both actin polymerization processes induced by Shigella during entry and intracellular spread seem to mimic mechanisms involved during the formation and modification of mammalian cytoskeletal structures (Ménard et al., 1996b; Cossart, 1997). Shigella entry-associated cytoskeletal rearrangements resemble the membrane ruffles induced by various stimuli, such as oncogenic activation (Bar-Sagi and Ferasmico, 1986), growth factors activation (Ridley and Hall, 1992) and Salmonella species (Finlay and Ruschkowski, 1991). However, very little is known about the molecular mechanisms and signaling cascades leading to cytoskeletal rearrangements and bacterial uptake during Shigella entry. The 
mechanism of actin polymerization for comet tail formation and intracellular motility induced by the IcsA protein of Shigella is also unclear (Bernardini et al., 1989). No direct interaction between IcsA and actin has been described. It is likely that recruitment of cytoskeletal regulators or effectors proteins by IcsA allows the nucleation and elongation of actin filaments at the bacterial surface. Several cytoskeletal proteins have been detected in Shigella actin tails and most of these proteins are present in regions of the cell undergoing rapid actin filament turnover such as the leading edge of lamellipodia. Thus, IcsA may mediate actin polymerization by mechanisms analogous to those involved during lamellipodial extension in spreading cells.

The small GTP-binding proteins of the Rho family, a subset of the Ras superfamily, are known to be key regulators of actin cytoskeletal dynamics (Van Aelst and D'Souza-Schorey, 1997; Hall, 1998). Their primary role is to act as molecular switches connecting external signals to the actin cytoskeleton through membrane receptors. Receptor-mediated signal transduction activates cytoplasmic regulatory proteins which, in turn, switch a GDP-bound inactive Rho to a GTP-bound active state. Activated Rho proteins interact with specific downstream effectors which induce specific cytoskeletal rearrangements. The mammalian Rho subfamily comprises more than 10 members including Rho (isoforms A, B, C, D, E), RhoG, Rac (isoforms 1, 2, 3), Cdc42/G25K. In adherent cell types, Rho, $\mathrm{Rac}$ and $\mathrm{Cdc} 42$ are part of an interconnected signaling pathway leading to the formation of specific cytoskeletal structures. In fibroblasts, Rho controls the formation of stress fibers, focal adhesion plaques and cell contractility (Ridley and Hall, 1992), Rac promotes the formation of ruffling lamellipodia (Ridley et al., 1992) and Cdc42 generates filopodia and the subsequent formation of lamellipodia (Kozma et al., 1995; Nobes and Hall, 1995). RhoG induces membrane ruffles, lamellipodia, filopodia, microvilli and partial loss of stress fibers, similar to those induced by Rac and Cdc42 (Gauthier-Rouvière et al., 1998). Rac and Cdc 42 have been shown to induce de novo actin polymerization in permeabilized platelets (Hartwig et al., 1995), in polymorphonuclear leukocytes and in Dictyostelium lysates (Zigmond et al., 1997), whereas Rho induces stress fibers assembly by bundling preexisting actin filaments (Machesky and Hall, 1997). Thus, Rac and Cdc42 are generally associated with de novo actin filaments polymerisation leading to cell surface protrusive structures formation and cell translational motility.

Shigella-induced membrane rearrangements have been shown to require functional Rho GTPases (Adam et al., 1996; Watarai et al., 1997). RhoA, B, C are recruited into the entry structure with a perivacuolar accumulation for RhoA. Inhibition of the Rho protein by a clostridial $\mathrm{C} 3$ chimeric toxin affects Shigella-induced membrane ruffling and bacterial entry. However, ultrastructural analysis of actin filaments in the entry structure shows that Rho is involved in the elongation and bundling steps (Adam et al., 1996). These results suggest that the nucleation of actin filaments during entry foci formation is controlled by other Rho members. In this study, we investigated the respective role of Rho, Rac, Cdc 42 and RhoG GTPases in Shigella entry. We observed the recruitment of endogenous Rac and Cdc42Hs in Shigella entry structures by immunofluorescence analysis. Using HeLa cells transiently overexpressing dominant negative forms of Rac and $\mathrm{Cdc} 42$
GTPases, we observed 3 to 4 times less bacterial uptake, suggesting a requirement of these GTPases during Shigella entry. Recently, actin-based rocketting motility of lipid vesicles in Xenopus extracts has been shown to require functional Cdc42 (Ma et al., 1998a,b; Moreau and Way, 1998) suggesting the involvement of this small GTPase in Shigella motility. We also investigated the role of Rho, Rac and Cdc42 in actin-based motility. We show here that Shigella-mediated actin comet tail formation was not affected in cells expressing any of the dominant inactive Rho proteins or in cells treated by the TcdB10463 clostridial toxin, a broad spectrum inhibitor of small GTPases. Therefore, while the actin cytoskeletal rearrangements leading to Shigella entry into epithelial cells appear to depend on active Rho GTPases, actin-mediated intracellular motility of Shigella is a Rho GTPase-independent event.

\section{MATERIALS AND METHODS}

\section{Bacterial strains, cell line and culture conditions}

Shigella flexneri strains used in this study are derivatives of the wildtype invasive strain M90T. SC301 is a M90T derivative expressing the AfaD afimbrial adhesin of uropathogenic Escherichia coli (Clerc and Sansonetti, 1987). All strains were grown in tryptic soy-broth and spectinomycin and ampicillin were used when required at $100 \mu \mathrm{g} / \mathrm{ml}$. HeLa cells were grown in minimal essential medium (MEM) containing $1 \mathrm{mM}$ glutamine, $0.1 \mathrm{mM}$ non-essential amino acids and $10 \% \mathrm{FCS}$ in a $5 \% \mathrm{CO}_{2}$ atmosphere. Semi-confluent HeLa cells grown for 48 hours on $22 \times 22 \mathrm{~mm}$ coverslips in 6-well tissue culture plates were used for transfection and infection with Shigella.

\section{Transient expression of c-myc or GFP-tagged proteins of the Rho family in HeLa cells}

Genes encoding constitutively active and dominant negative forms of Rho (RhoA isoform), Rac ( $\mathrm{Rac} 1$ isoform) and Cdc42 (G25K isoform) were introduced in a pRK5myc vector allowing expression of c-myc tagged GTPases. Plasmids allowing expression of GFP-tagged RhoG active and inactive GTPase forms have recently been described (Gauthier-Rouvière et al., 1998). HeLa cells were transfected with 10 $\mu \mathrm{g}$ of plasmid by standard calcium phosphate technique for 24 hours or 48 hours before infection by Shigella.

\section{Infection of HeLa cells with Shigella}

HeLa cells were infected as previously described (Adam et al., 1996). Overnight cultures of Shigella were diluted in tryptic soy broth and grown to mid-exponential phase, centrifuged at 5,000 $g$ for 5 minutes, washed and resuspended in MEM, $50 \mathrm{mM}$ Hepes, $\mathrm{pH} 7.5$, to bring the suspension to a concentration of $10^{8}$ bacteria/ml (M90T) or $10^{7}$ bacteria/ml (SC301). Untransfected or transfected HeLa cells were washed three times with MEM, then overlaid with the respective bacterial suspensions. When infecting with M90T, bacteria were centrifugated onto cells for 10 minutes at $800 \mathrm{~g}$. Dishes were then set on top of a $37^{\circ} \mathrm{C}$ water bath for various times. For entry studies, infection was stopped by three washes in PBS at room temperature. For entry quantification and intracellular motility studies, infected cells were washed with MEM five times and incubated with MEM, $50 \mathrm{mM}$ Hepes, $\mathrm{pH} 7.5$, with $50 \mu \mathrm{g} / \mathrm{ml}$ of gentamicin for a further 2 hours at $37^{\circ} \mathrm{C}$.

\section{Analysis of actin-based motility in HeLa cells treated with clostridial toxin}

C. difficile exotoxin TcdB-10463 was a kind gift of Dr Christoph von Eichel-Streiber and was prepared as described previously (von Eichel- 
Streiber et al., 1987). HeLa cells were infected by M90T by centrifugation followed by a 30 minutes incubation at $37^{\circ} \mathrm{C}$. After several washes, infected cells were treated for 2 hours with $1 \mu \mathrm{g} / \mathrm{ml}$ of TcdB 10463 in MEM, $50 \mathrm{mM}$ Hepes, pH 7.5. Gentamicin (50 $\mu \mathrm{g} / \mathrm{ml})$ and chloramphenicol $(3 \mu \mathrm{g} / \mathrm{ml})$ were, respectively, added to kill extracellular bacteria and to inhibit intracellular bacterial protein synthesis. After 2 hours, both antibiotics were removed by several washes and infected cells were incubated for a further 3 hours to allow bacterial multiplication and spreading in the presence of the TcdB10463 toxin.

\section{Immunofluorescence analysis}

Infected cells on glass coverslips were fixed with $3.7 \%$ paraformaldehyde in PBS for 30 minutes. After washes, excess aldehyde groups were quenched with $\mathrm{NH}_{4} \mathrm{Cl} 50 \mathrm{mM}$ in PBS for 10 minutes. The cells were permeabilized with $0.2 \%(\mathrm{v} / \mathrm{v})$ Triton X-100 in PBS for 10 minutes, saturated 30 minutes in 2\% PBS-BSA and then incubated with specific mono- or polyclonal antibodies. For labelling of endogenous Rho GTPases, fixed and quenched preparations were permeabilized with methanol, according to manufacturer's recommendations. Primary antibodies used in this study are RhoA specific polyclonal 119 (Santa Cruz Biotechnology, CA), Rac1 specific polyclonal C-14 antibodies (Santa Cruz Biotechnology, CA) or monoclonal antibody clone 23A8 (UBI), Cdc42Hs specific polyclonal P1 (Santa Cruz Biotechnology, CA), anti-c-myc monoclonal antibody 9E10 (kindly provided by F. Gaudeau, CHU Necker, Paris) and $S$. flexneri 5a LPS specific polyclonal antibodies. These primary antibodies were visualized by subsequent incubation with the respective Texas Red- (Amersham, France), Cy5- (Jackson Immunoresearch Laboratories, Indianapolis, IN) or FITC-conjugated secondary antibodies. Polymerized actin was stained by incubation with bodipy-phallacidin (Molecular Probes, Eugene, OR) or anti-actin monoclonal antibody (Boehringer Mannheim, France). Preparations were either examined with a conventional fluorescence microscope (BH2 RFCA, Olympus Optical Co. Ltd) or a confocal laser scanning microscope (Zeiss Axiophot).

\section{Quantification of Shigella entry into transfected cells}

HeLa cell preparations transfected with GTPases plasmids were infected with Shigella M90T strain for 1 hour, washed and incubated for 1 hour in the presence of $50 \mu \mathrm{g} / \mathrm{ml}$ of gentamicin. Cells were labelled with monoclonal anti-myc 9E10 and polyclonal anti-LPS antibodies. Infected cells (containing more than three bacteria) were identified and classified according to the c-myc staining in transfected and in untransfected cells.

\section{Analysis of bacterial movement in Xenopus eggs extracts}

Interphasic cytoplasmic extracts of unfertilised Xenopus eggs were prepared in XB buffer as described (Marchand et al., 1995). Escherichia coli expressing the membrane form of IcsA (strain MC4100 $\Delta$ ompT harboring an pUC8-based icsA gene) was grown in $2 \mathrm{YT}$ at mid-exponential phase and kept frozen in $30 \%$ glycerol at $80^{\circ} \mathrm{C}$. Motility assays were performed by mixing $10 \mu \mathrm{l}$ of thawed Xenopus extracts supplemented with $4 \mathrm{mM}$ of F-actin, $0.5 \mathrm{mM}$ of ATP/ $\mathrm{MgCl}_{2}, 0.01 \%$ of methyl cellulose, $30 \mathrm{mM}$ creatine phosphate, and $3 \mathrm{mM}$ rhodamine-actin. Bacteria were spun down at 4,000 $\mathrm{g}$ for 5 minutes at $22^{\circ} \mathrm{C}$, resuspended in $\mathrm{XB}$ buffer and added to the extracts mixture. Xenopus extracts were diluted twofold by addition of all components. An aliquot of $2.5 \mu \mathrm{l}$ of the mixture was squashed between a $22 \times 22 \mathrm{~mm}$ coverslip and a slide, incubated for 5-30 minutes at room temperature. When required, Xenopus extracts were supplemented with $1 \mathrm{mM}$ of guanosine 5'-O-(3-thiotriphosphate) (GTP $\gamma$ S) (Sigma Co, France). Small GTPases present in the extracts were inactivated by a treatment with $15 \mathrm{nM}$ of TcdB-10463 at room temperature for 30 minutes. Fluorescence microscopy observations and data acquisition were carried out as previously described (Marchand et al., 1995).

\section{RESULTS}

\section{RhoA, Rac1 and Cdc42Hs proteins are recruited in Shigella entry structures}

In order to visualise the potential recruitment of Rac1 and Cdc42Hs during Shigella entry, semi-confluent HeLa cells were infected, fixed, double stained for F-actin and for the respective GTPases and analyzed by confocal microscopy (shown in Fig. 1). The observations presented here are made on untransfected cells and reflect the endogenous GTPase recruitment. Cdc $42 \mathrm{Hs}$ was observed to be recruited to the site of bacterial entry, strictly colocalizing with areas of actin polymerization (Fig. 1a,b,c). Rac was also observed in the entry structure (Fig. 1d,e,f). Similar patterns of staining for Rac1 and $\mathrm{Cdc} 42 \mathrm{Hs}$ were observed with polyclonal or monoclonal antibodies against Rac1 and Cdc42Hs from different origin (data not shown), excluding the possibility of cross-reactivity between Rac1 and Cdc42Hs. The previous observation of Rho (A, B, C) recruitment to the entry foci (Adam et al., 1996) was also confirmed (Fig. 1g,h,i).

\section{Rho, Rac, Cdc42, but not RhoG are necessary for Shigella entry into HeLa cells}

To examine the functional role of Rho, Rac, Cdc42 and RhoG in Shigella entry into HeLa cells, we analyzed the ability of cells expressing dominant negative Rho, Rac, Cdc42 and RhoG to internalize Shigella. Analysis of the HeLa cells transfected with dominant active forms of Rho, Rac and Cdc42 induced specific cytoskeletal rearrangements that have been previously described (Dutartre et al., 1996); Cdc42V12 induced microspikes and podosomes, RacV12 induced lamellipodia and RhoAV14 generated actin stress fibers (data not shown). Cells expressing dominant negative forms of Rho, Rac and Cdc42 exhibited a severe breakdown of the actin cytoskeleton compared to untransfected cells (data not shown). No such spectacular actin cytoskeletal changes were observed with cells transfected with the activated or dominant negative forms of RhoG.

Transfected cells were infected with M90T, the wild-type Shigella strain, at $37^{\circ} \mathrm{C}$ for 1 hour, washed and treated with gentamicin for a further 1 hour. Transfected cells and intracellular bacteria were identified with anti-myc and antiLPS antibodies, respectively. Fig. 2 shows a confocal microscopy view of cells expressing dominant active/negative GTPases (shown in red) and intracellular bacteria (shown in green). Cells expressing dominant negative forms of Cdc42 (b), Rac (d) and Rho (f) contained few intracellular bacteria, compared to neighbouring non-transfected cells (shown in the insert in the upper right part of each panel), or cells expressing the respective dominant active forms ( $\mathrm{a}, \mathrm{c}$ and $\mathrm{e})$. No difference in internalization was observed between cells expressing the dominant active and negative forms of RhoG ( $g$ and $h$ ). These results suggested a defect in bacterial internalization in cells expressing the dominant negative forms of Rho, Rac and Cdc42.

Entry levels were quantified in transfected cells, as described in Materials and Methods and are shown in Fig. 3. In untransfected cells, $45 \pm 10 \%$ of the total cell population was infected by Shigella. Quantitative analysis was only considered with cells expressing medium levels of GTPases. Bacterial entry into cells expressing high levels of dominant active 
Fig. 1. Localization of Cdc42Hs, Rac1 and RhoA in Shigella entry structure in HeLa cells. HeLa cells were infected with Shigella flexneri SC301 strain, double stained with anti-GTPases and with anti-actin antibodies. Confocal microscopy analysis of Rho GTPases labelling (red staining) shows that Cdc42Hs (a), Rac1 (d), RhoA (g) are present in Shigella entry structures (indicated by arrows) visualised here by F-actin staining (b,e,h) and phase contrast $(\mathrm{c}, \mathrm{f}, \mathrm{i})$. Bar in $\mathrm{i}$ is valid for all panels.
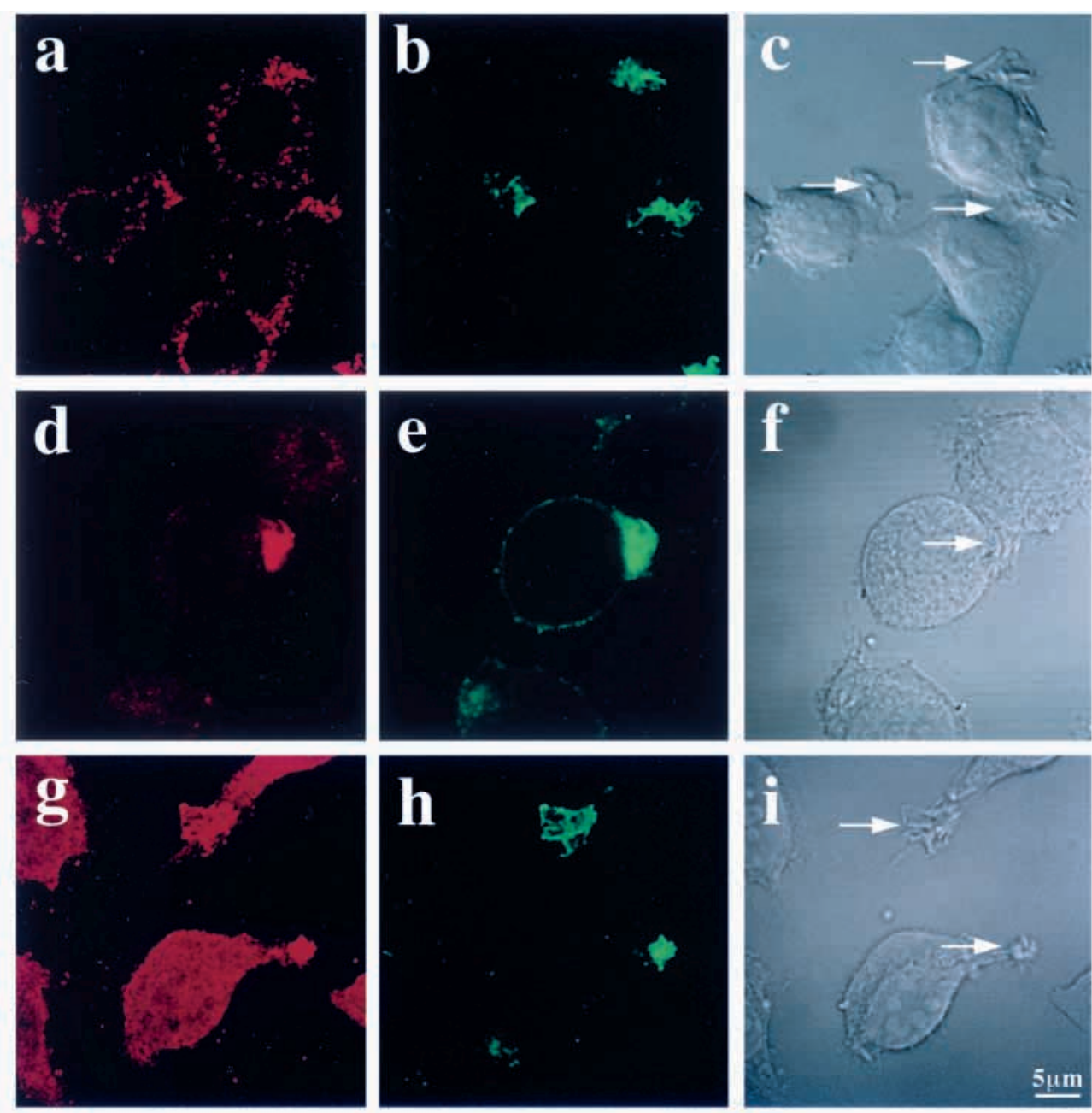

GTPase was significantly decreased, most likely due to severe cytoskeletal alterations. Cells expressing medium levels of dominant active forms of Rac, Cdc42 and RhoG exhibited the same level of bacterial internalization as untransfected cells $(100 \pm 10 \%$ for untransfected cells, $97 \pm 25 \%$ for RacV12expressing cells, $112 \pm 42 \%$ for Cdc42V12-expressing cells, and $68 \pm 4 \%$ RhoGV12-expressing cells). Overexpression of RhoV14 induced a decrease in the entry efficiency, which was likely due to cell contraction. Only $32 \pm 12 \%$ and $26 \pm 6 \%$ of cells expressing dominant negative forms of Rac and $\mathrm{Cdc} 42$ were, respectively, infected. Thus, expression of dominant negative $\mathrm{Rac}$ and $\mathrm{Cdc} 42$ led to 3.5 and 4-fold decrease in bacterial internalization. No obvious differences between cells expressing active and dominant negative forms of RhoG were observed. These results indicate that $\mathrm{Rac}$ and $\mathrm{Cdc} 42$ are important for Shigella internalization into epithelial cells.

\section{Decreased size of Shigella-induced entry foci in HeLa cells expressing dominant negative Rho, Rac, and Cdc42 proteins}

In order to characterize the internalization defects observed in cells expressing dominant negative GTPases, we analyzed the structure of Shigella-induced membrane ruffles in these cells. Untransfected HeLa cells infected by Shigella strain SC301 showed F-actin accumulation associated with entering bacteria (Fig. 4a' , b'). In cells expressing activated Cdc42, Rac, and Rho,
F-actin accumulation in the entry foci was similar to that observed in control cells (Fig. $4 \mathrm{c}^{\prime}, \mathrm{e}^{\prime}, \mathrm{g}^{\prime}$ ). In cells expressing dominant negative Cdc42, Rac or Rho, F-actin accumulation was lower compared to control cells or cells expressing dominant active proteins (Fig. $4 \mathrm{~d}^{\prime}, \mathrm{f}^{\prime}, \mathrm{h}^{\prime}$ ). Decrease of actin content was more pronounced in the foci formed in cells expressing dominant negative Cdc42. No difference in F-actin accumulation in Shigella entry foci was evident between cells expressing activated and dominant negative RhoG (Fig. 4i',j'). These results suggest that, like Rho, Rac and $\mathrm{Cdc} 42$ are also required for the actin polymerization process leading to Shigella entry but that RhoG is not involved.

\section{Shigella actin comet tail formation is not impaired in HeLa cells expressing dominant negative forms of Rho, Rac and Cdc42 proteins}

In order to analyze the potential effect of the Rho family members during Shigella intracellular movement, cells expressing activated and dominant negative Rho, Rac and Cdc42 were infected with Shigella M90T strain for 2 hours, fixed and labelled with bodipy-phallacidin and 9E10 mAb to visualize comet tail formation inside transfected cells. Expression of activated GTPases did not affect the formation of Shigella actin tails (Fig. 5b,f,j). Although the entry process was affected in cells expressing dominant negative forms, comet tail formation of internalized Shigella occured with the same 
efficiency as untransfected cells (Fig. 5d,h,l). Interestingly, Shigella comets in cells expressing dominant negative Rho proteins were longer and exhibited higher F-actin content, probably due to higher availability of G-actin. These data show that specific inactivation of each member of the Rho subfamily has no effect on the actin comet formation of Shigella.

\section{Treatment of HeLa cells with the clostridial toxin TcdB-10463 does not affect actin comet tail formation by Shigella}

To inactivate all members of the Rho subfamily simultaneously, HeLa cells were treated with TcdB-10463 toxin which irreversibly inactivates Rho, Rac and Cdc42Hs.
HeLa cells were treated with $1 \mu \mathrm{g} / \mathrm{ml}$ of TcdB-10463 for 2 hours and F-actin was visualised. Untreated HeLa cells appeared flat with well-organised stress fibers (Fig. 6a). After a 2 hours treatment of these cells with TcdB-10463, cell rounding was observed with loss of stress fibers, retraction of the cytoplasm, peripheral localization of the nucleus and appearance of retraction fibers (Fig. 6c). Since TcdB-10463 treatment of HeLa cells efficiently inhibits Shigella entry (Adam et al., 1996), untreated HeLa cells were first infected and then treated with TcdB-10463 toxin. Intracellular Shigella comet tails could still be observed under these conditions, although these were harder to detect due to the round morphology of cells (data not shown). Moreover, Shigella was
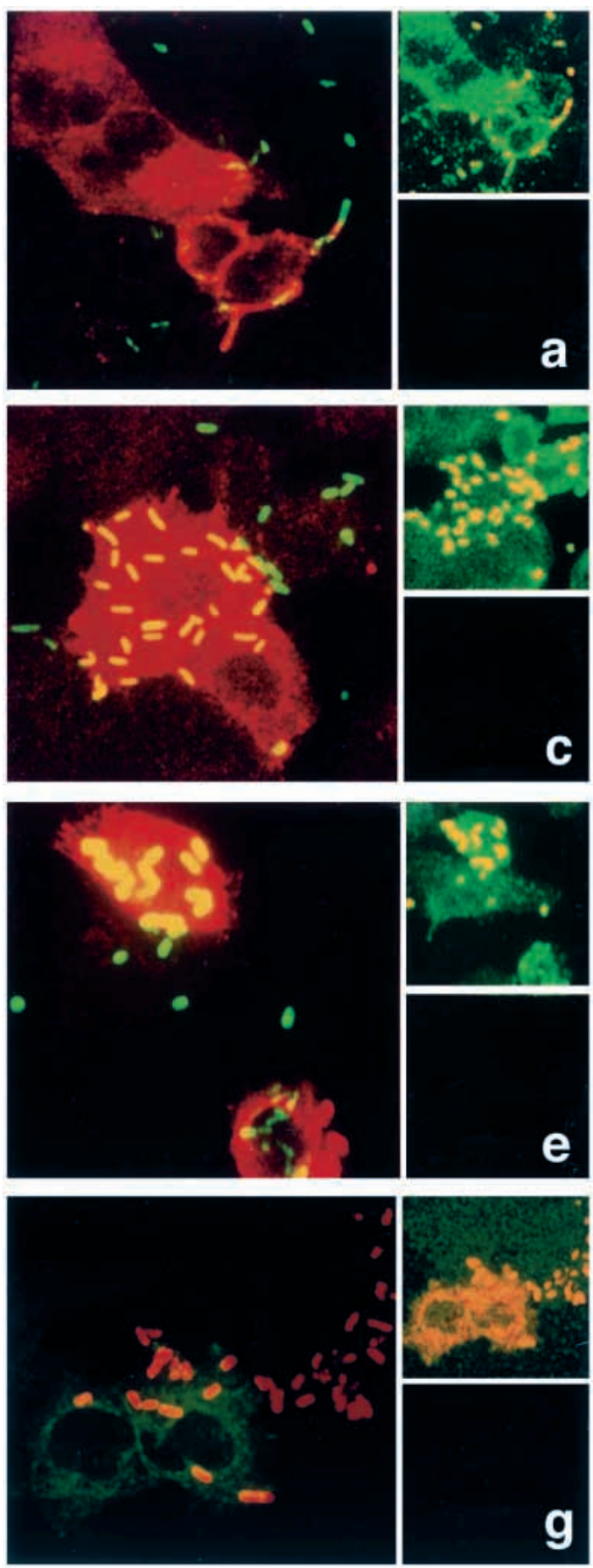
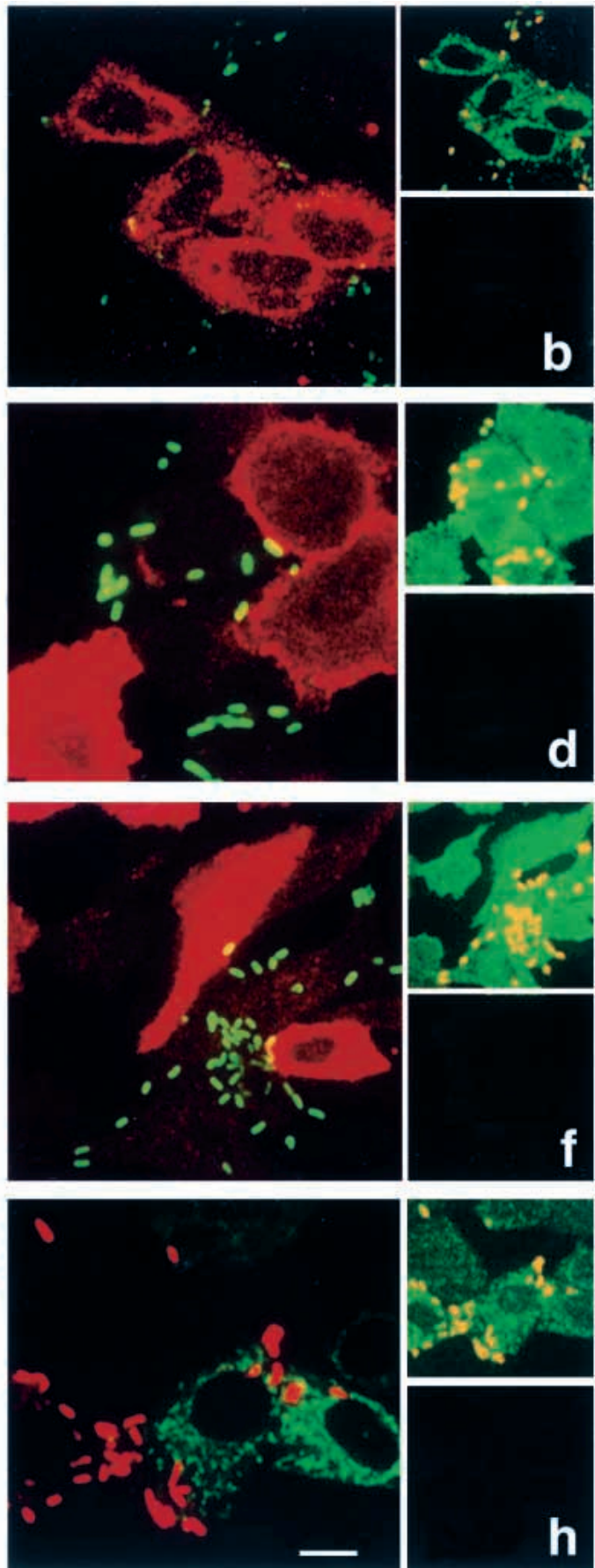

Fig. 2. Shigella uptake by HeLa cells expressing dominant positive and negative $\mathrm{Cdc} 42$, Rac, Rho and RhoG. HeLa cells were transfected with plasmids encoding for Cdc42V12 (a), Cdc42N17 (b), RacV12 (c), RacN17 (d), RhoV14 (e) and RhoN19 (f), GFP-RhoGV12 (g) and GFP-RhoGN17 (h).

Transfected cells were infected with Shigella M90T strain for 2 hours, fixed, stained with antibodies and analysed by confocal microscopy. (a,f) Infected cells were labelled with the monoclonal antibody 9E10 to visualise myc-GTPases expression (shown in red) and anti Shigella LPS polyclonal to localise intracellular bacteria (shown in green). (g,h) Infected cells were stained with anti Shigella LPS polyclonal antibodies to localise intracellular bacteria (shown in red) and GFP-RhoG transfected cells (shown in green). In the top right panel, cells present in the optical field with

intracellular bacteria are shown. Bar, $10 \mu \mathrm{m}$, valid for all panels. 

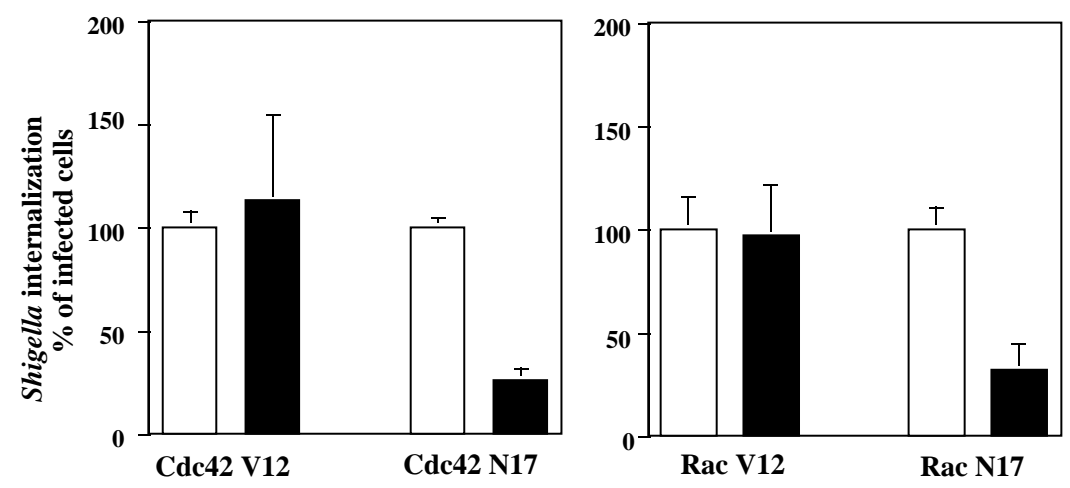

Fig. 3. Inhibition of Shigella uptake by cells expressing dominant negative Rho GTPases. HeLa cells were transfected with plasmids allowing expression of Rho GTPases and subsequently infected with Shigella M90T, double stained with an anti-myc monoclonal antibody and with an anti-Shigella LPS to visualise transfected cells and intracellular bacteria, respectively. Infected cells were classified into transfected and untransfected cells according to the myc staining. Results show mean \pm s.d. of the percentage of infected cells among untransfected cells (open bars) and transfected cells (full bars) and represent a combination of five independent experiments. For each category, at least 250 transfected cells were examined.
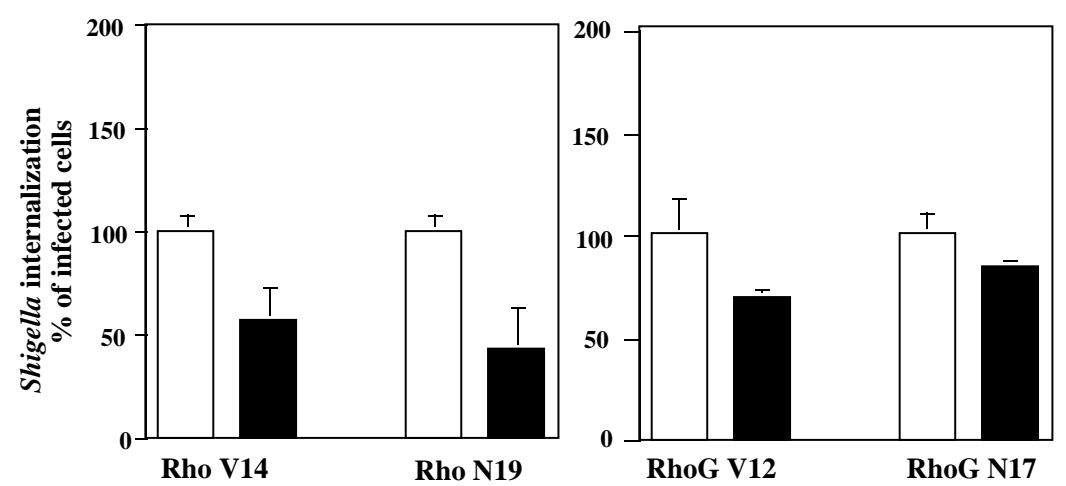

able to induce formation of cellular protrusions containing bacteria-associated actin tails in TcdB-10463 treated HeLa cells (Fig. 6d, arrows). These results indicate that simultaneous inactivation of all members of the Rho subfamily did not compromise Shigella actin comet formation.

\section{GTP $\gamma$ S or TcdB-10463 toxin have no effect on IcsA- mediated actin-based motility in Xenopus extracts}

To investigate a potential effect of small GTPases on the rate of IcsA-mediated movement, bacterial spread was analyzed using IcsA-expressing E. coli in Xenopus extracts, as Shigella is not able to induce actin polymerization in these extracts (Kocks et al., 1995; Goldberg and Theriot, 1995). As reported, GTP $\gamma \mathrm{S}$ addition to low speed Xenopus extracts induced the formation of actin nucleation foci and increased the number of vesicle-associated actin comets. Vesicle motility was observed 5-10 minutes after GTP $\gamma \mathrm{S}$ addition and up to 30 minutes with a mean movement rate of $10 \mu \mathrm{m} /$ minute $(n=10)$. Bacteria induced comet tails in these extracts after a lag period of 30 minutes and moved at $7 \mu \mathrm{m} /$ minute (s.d.=1.3, $n=12$ ) (Fig. 7A,c,d and Fig. 7B) which was similar to what was observed in untreated extracts, i.e. $8.2 \mu \mathrm{m} /$ minute (s.d. $=0.9, n=18$ ) (Fig. 7A,a,b and Fig. 7B). These results suggest that the activation of small GTPases has no effect of the rate of movement.

Inactivation of endogenous Rho proteins was obtained by 30 minutes incubation at room temperature with $15 \mathrm{nM}$ of TcdB10463 toxin. Subsequently, addition of GTP $\gamma S$ failed to induce actin foci formation and lipid vesicle actin-based motility, suggesting an efficient inactivation of $\mathrm{Cdc} 42$ and probably also of the other members of the Rho subfamily. Nevertheless, bacterial motility in the TcdB-treated extracts was similar to that observed in untreated extracts and occured at 6.3 $\mu \mathrm{m} /$ minute (s.d.=1.3, $n=31$ ) (Fig. 7A,e,f and Fig. 7B). Addition of GTP $\gamma \mathrm{S}$ to the TcdB-treated extracts also had no effect on bacterial motility (data not shown). These results confirmed that small GTPases of the Rho subfamily have no effect on the rate of movement.

\section{DISCUSSION}

The actin cytoskeleton is a highly dynamic structure involved in diverse cellular functions including maintenance of cell integrity, subcellular distribution of organelles, induction of morphological changes, and translational motility. In order to regulate its plasticity, the cytoskeleton is under strict control mechanisms. These mechanisms have been selected as targets for invading bacterial and viral pathogens to promote their

Fig. 4. F-actin accumulation in Shigella entry structure in cells expressing the dominant active and negative Rho GTPases. Rho GTPases transfected HeLa cells were infected with Shigella SC301 strain, fixed and stained for immunofluorescence.

(a, $\left.\mathrm{a}^{\prime}, \mathrm{b}, \mathrm{b}^{\prime}\right)$ Untransfected HeLa cells, infected by Shigella, were Factin stained to visualise entry structures (shown in green, arrows) and LPS stained to localise invading bacteria (shown in red).

(c-j') Transfected HeLa cells infected by Shigella were myc stained to visualise transfected cells (shown in red), F-actin stained (shown in green) and Shigella LPS stained to localise invading bacteria (shown in magenta). HeLa cells were transfected with plasmids expressing Cdc42V12 (c,c'), Cdc42N17 (d,d'), RacV12 (e, e'), RacN17 (f, f'), RhoV14 (g,g'), RhoN19 (h,h'), GFP-RhoGV12 (i,i'), GFP-RhoGN17 (j,j'). Bar, $10 \mu \mathrm{m}$, valid for all other panels. 
Rho GTPases during epithelial cell invasion by Shigella

2075
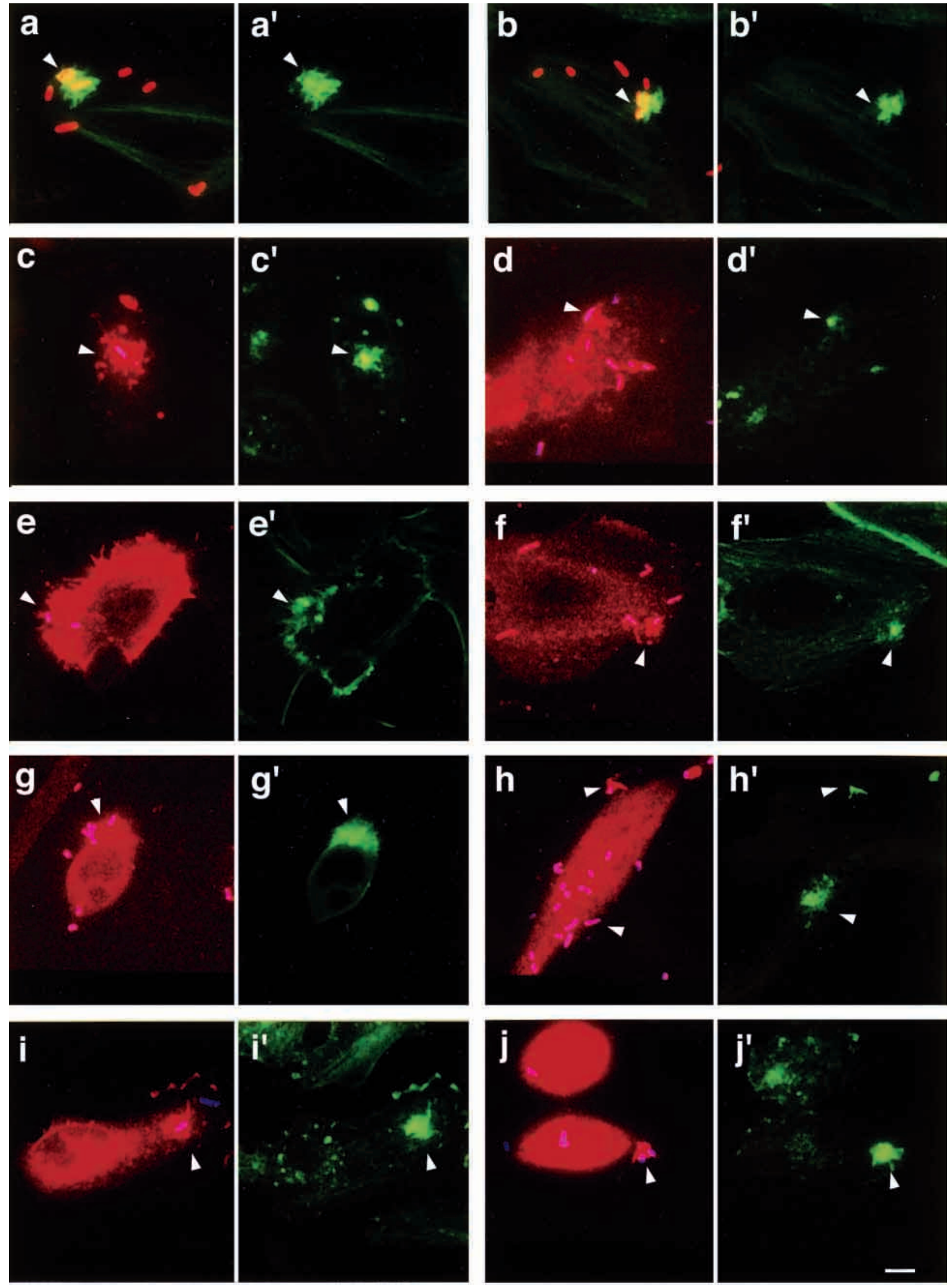

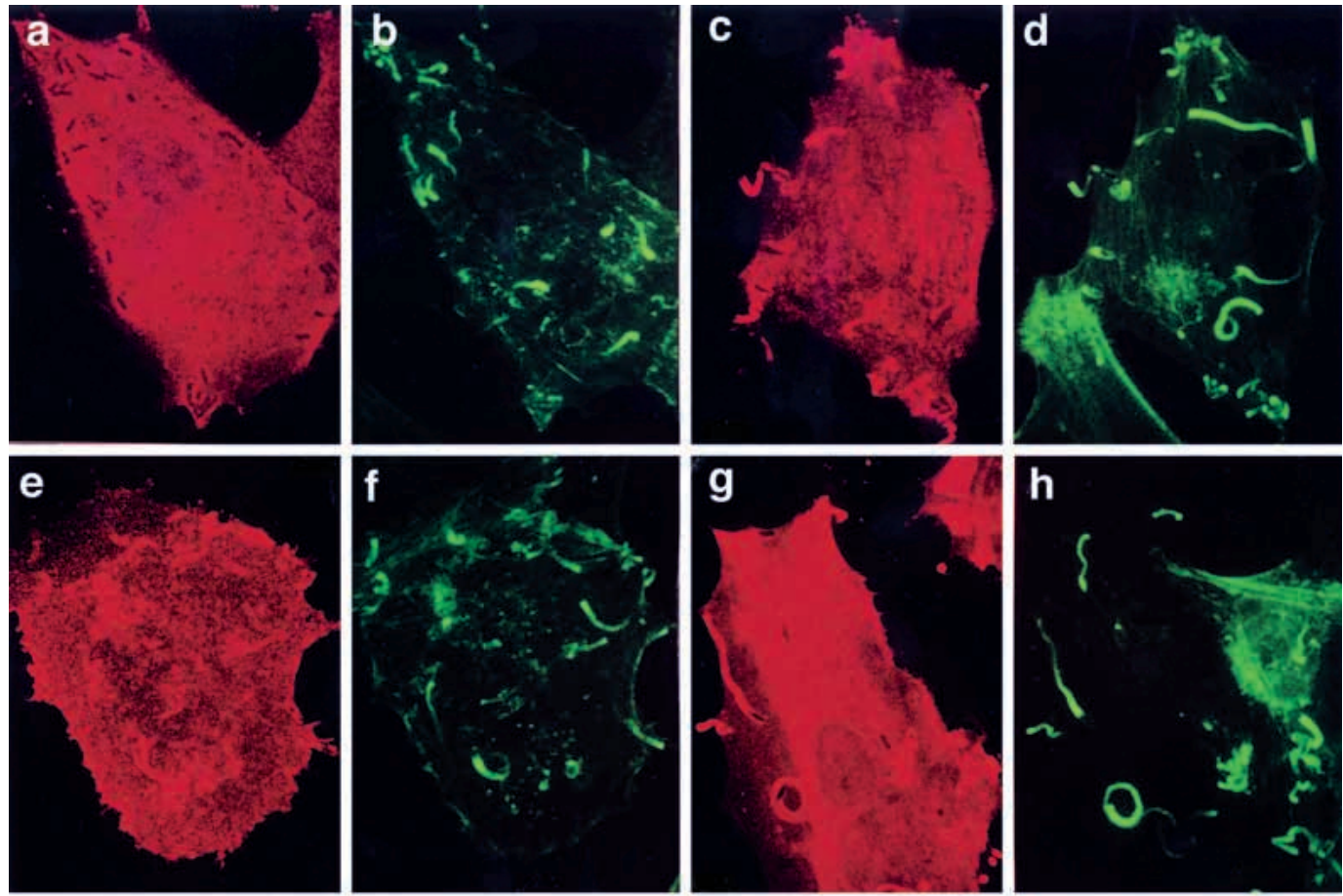

Fig. 5. Shigella F-actin comet tail formation in HeLa cells expressing the dominant active
and negative Rho GTPase. Cells transfected with $\mathrm{Cdc} 42 \mathrm{~V} 12$ (a,b), Cdc42N17 (c,d), RacV12 (e,f), RacN17 (g,h), RhoV14 $(\mathrm{i}, \mathrm{j})$, RhoN19 (k,l) were infected with Shigella M90T strain for 2 hours. Infected cells were double labelled with monoclonal anti-myc antibody, to visualise GTPases expression (a,c,e,g,i,k) and with bodipy phalloidin to stain F-actin (b,d,f,h,j,l). Bar, $5 \mu \mathrm{m}$, valid for all other panels.
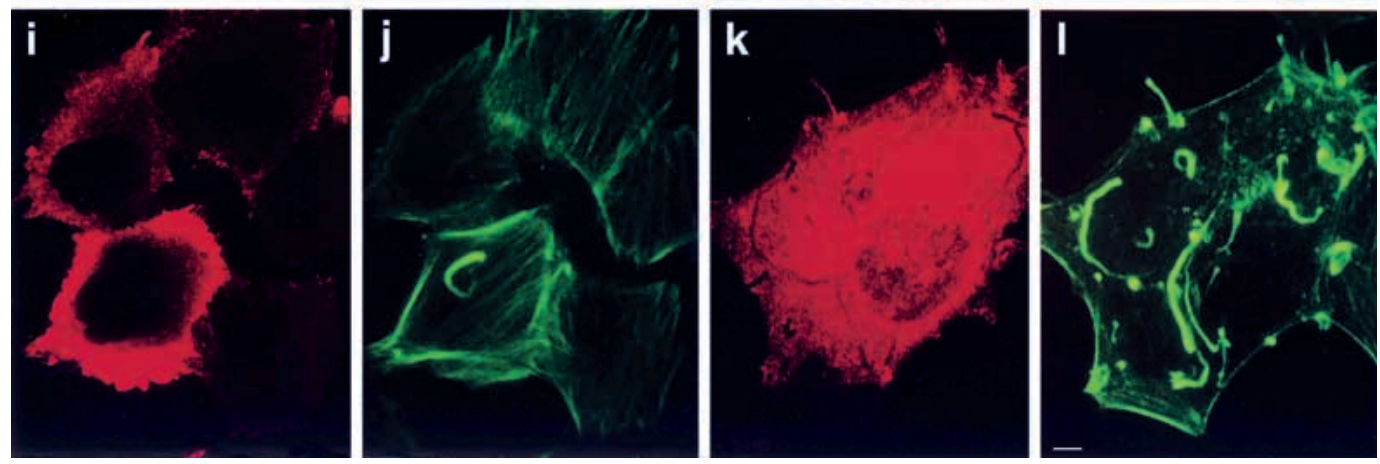

entry into mammalian cells (Finlay and Cossart, 1997). In this study, we have investigated the entry and intracellular spread of Shigella, a facultative intracellular bacterial pathogen. Both Shigella entry and movement within the infected cell require the formation of cytoskeletal structures, reminiscent of integrated structures that normally exist in mammalian cells (Ménard et al., 1996b; Cossart, 1997). Although the mechanisms leading to actin assembly/disassembly in eukaryotic cells are still poorly understood, recent work has identified members of the Rho subfamily of small GTPases (Rho, Rac and Cdc42) as key regulators of these processes (Hall, 1998). Requirement of Rho GTPase during Shigella entry has been described (Adam et al., 1996; Watarai et al., 1997). Inactivation of Rho blocks Shigella-induced actin filament elongation and bundling but not actin nucleation (Adam et al., 1996), thus it was important to investigate whether Shigella-induced actin nucleation processes are dependent on Rac and Cdc42. The potential involvement of the Rho GTPases during Shigella motility was not analysed until now.

We have shown here that $\mathrm{Cdc} 42 \mathrm{Hs}$ and Rac1 are recruited into the Shigella entry structure. In contrast to RhoA, which is closely associated with the vacuolar membrane that surrounds the entering bacterial body (Adam et al., 1996), Cdc42Hs and Rac1 were associated with the cytoskeletal projections that support the entry structure. Transfection of HeLa cells with dominant negative forms of $\mathrm{Cdc} 42$ and Rac caused a 3- to 4fold decrease in the efficiency of bacterial internalization, indicating the functional relevance of their recruitment into the entry structure. Inactivation of $\mathrm{Cdc} 42$ and Rac leads to Shigella-induced actin polymerization defects and to smaller entry foci which probably account for the inhibition of bacterial internalization.

Proteins involved in focal adhesion plaque formation are recruited into the entry structure. This include structural proteins, such as vinculin, paxillin, talin, $\alpha$-actinin, plastin, and signaling proteins, such as pp $125^{\mathrm{FAK}}$, pp60 $0^{c-s r c}$ and Rho (Adam et al., 1995, 1996; Tran Van Nhieu et al., 1997; Dumenil et al., 1998). It was thus speculated that Shigella induces focal adhesion-like structures to mediate bacterial uptake (Ménard et al., 1996b). However, our results clearly favor a model in which the Shigella entry focus is more sophisticated than a focal adhesion-like structure. Growing evidence suggest that $\mathrm{Cdc} 42$ and Rac are involved in de novo actin polymerization (Hartwig et al., 1995; Zigmond et al., 1997, 1998). Thus, both Cdc42 and Rac are likely involved in 
the massive burst of actin polymerization and the formation of microspikes and lamellipodia observed during Shigella entry. This initial entry focus would be subsequently remodelled by RhoA activation, which would lead to formation of the focal adhesion-like structure, directly involved in the bacterial uptake. These results extend the complexity of signaling pathways activated during Shigella entry and also render the model of a single adherence plaque for Shigella entry insufficient. The observations made in this work also raise the question of how these three GTPases are activated during Shigella entry. Bacterial invasion protein (Ipa) are major effectors of Shigella entry (Ménard et al., 1996a). Ipa proteins are secreted upon bacterial contact with host cell and are likely translocated into cell cytoplasm by a specific secretory machinery, the type III Mxi-Spa apparatus. Translocation of a Ipa protein into the host cell could activate simultaneously all three GTPases. This Ipa protein could act on one of the GTPase regulatory factors, i.e. activate a common guanine exchange factor (GEF), neutralize a common GTPase-activating protein (GAP), or affect an inhibitory molecule such as RhoGDI. An alternative possibility is that the Ipa protein activates directly $\mathrm{Cdc} 42$ which in turns activates Rac and Rho in a interconnected cascade, as described in fibroblasts (Nobes and Hall, 1995).

$\mathrm{Cdc} 42$ and Rac involvement during other bacterial or particle uptake have been described. Salmonella typhimurium induce cytoskeletal structures similar to those observed during Shigella entry into host cell. Recent work has shown that Cdc42 is required for Salmonella entry (Chen et al., 1996) and that the Salmonella SopE protein induces membrane ruffling by acting as a GEF for Cdc42 and Rac (Hardt et al., 1998). However, there are clear differences between these two invasion processes, such as the lack of Rho involvement in Salmonella entry (Jones et al., 1993) compared to its clear involvement in the case of Shigella (Adam et al., 1996; Watarai et al., 1997). Recently, Fc $\gamma$ receptor-mediated phagocytosis, which elicits major cellular projections, has also been shown to require Cdc42 and Rac (Massol et al., 1998, Caron and Hall, 1998). However, the precise function of these proteins in the internalization process is unclear. Thus, it seems that Rac and $\mathrm{Cdc} 42$ are both required during internalization process involving subcortical massive actin polymerization and cell surface rearrangements.

The possible involvement of Rho GTPases in the actin
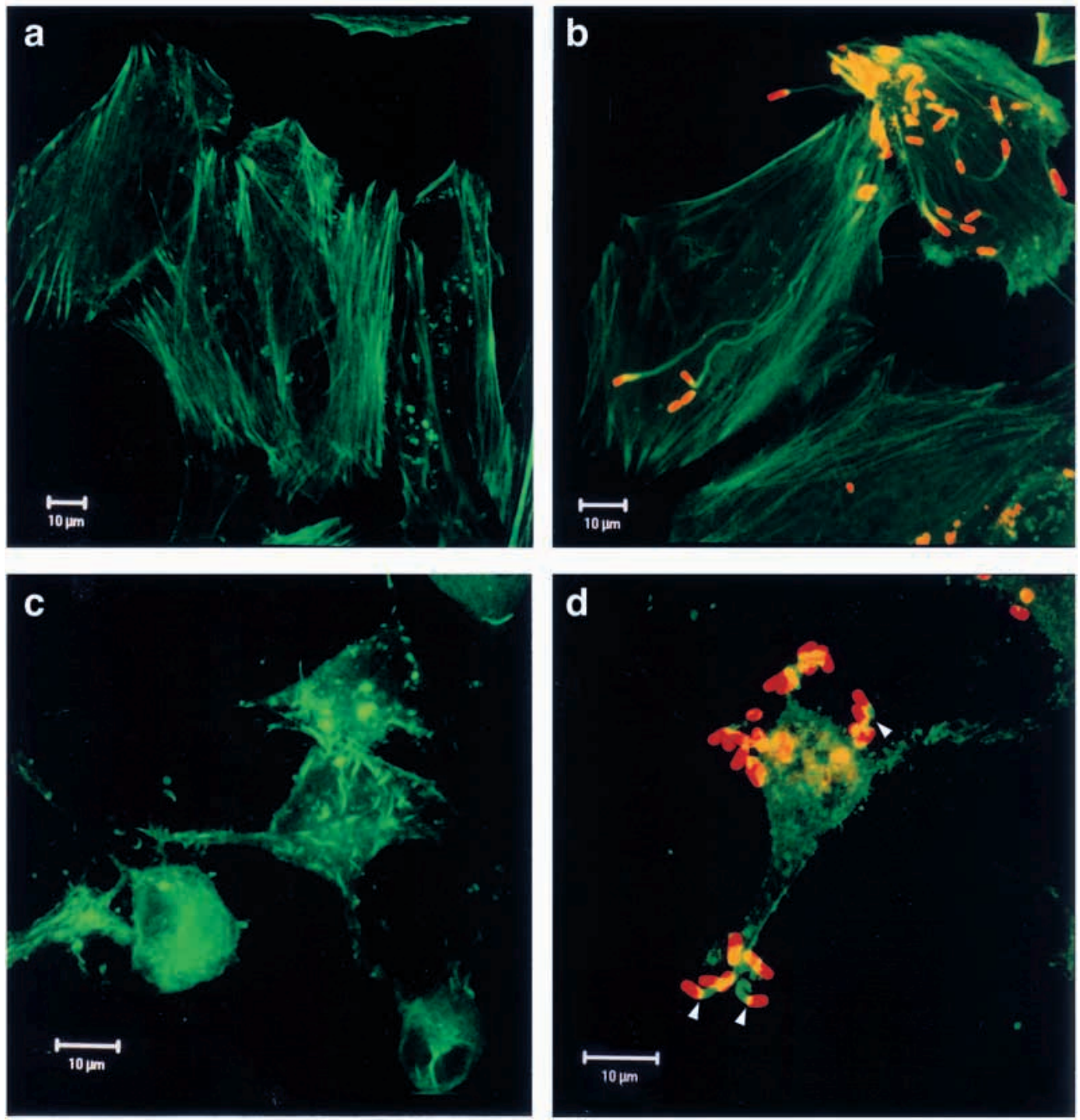

Fig. 6. Shigella F-actin comet tail formation in HeLa cells treated with TcdB-10463 toxin. Untreated HeLa cells and TcdB-treated cells were stained with bodipy phalloidin to visualise F-actin (respectively, a and c). Untreated HeLa cells were infected with Shigella M90T strain for 30 minutes, then treated with gentamicin for 3 hours (b) or with chloramphenicol, gentamicin and TcdB-10463 toxin for 2 hours and chloramphenicol was removed for a further 3 hours (d). Infected cells were double labelled with anti Shigella LPS, to visualise intracellular bacteria (shown in red), and bodipy phalloidin to stain Factin (shown in green). 
A
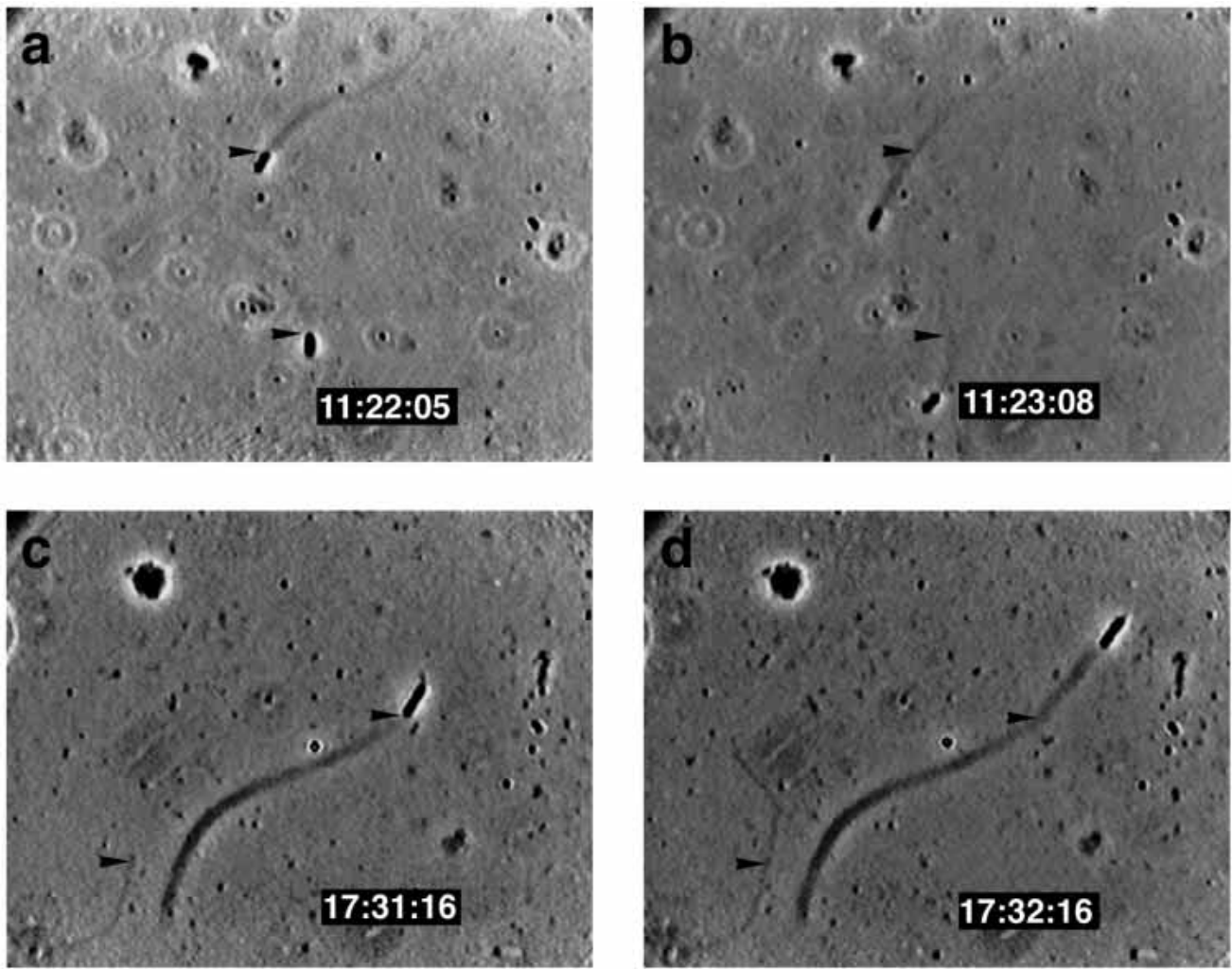

Fig. 7. E. coli comet tail formation in Xenopus egg extracts treated with TcdB-10463 toxin. (A) Movement of E. coli expressing IcsA in Xenopus extracts. The same field was observed during 5 minutes by phase contrast. Arrowheads indicate the initial position of bacteria. (a,b) Movement of bacteria in control extracts. (c,d) Movement of bacterium and vesicle (left arrowhead) in GTP $\gamma$ S-treated extracts. (e,f) Movement of bacteria in TcdB-treated extracts. Time is indicated in each panel. Bar, $5 \mu \mathrm{m}$, valid for all panels. (B) Rate of bacterial movement in extracts treated with GTP $\gamma \mathrm{S}$ and TcdB toxin. Results represent mean \pm s.d. of three independent experiments with 20 bacteria analysed in each sample.
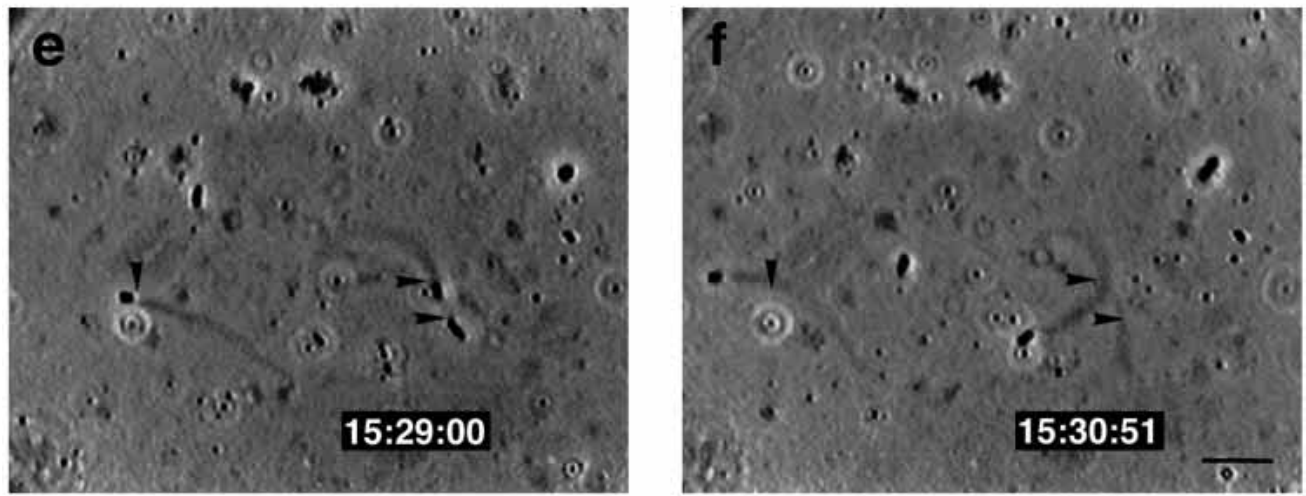

B

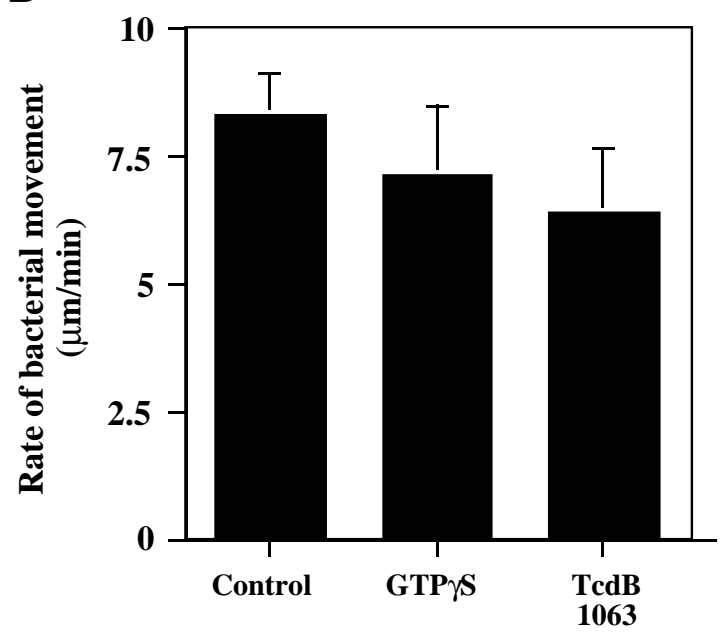


polymerization process during Shigella intracellular motility was also analysed. Using HeLa cells expressing dominant negative Rho GTPases and HeLa cells treated with the TcdB10463 toxin, a Rho GTPases-inhibitor, we have shown that inactivation of Rho GTPases does not compromise Shigella comet tail formation. Moreover, treatment of Xenopus extracts by TcdB-10463 toxin did not affect the rate of motility. Efficient inactivation of Rho GTPases by the toxin was confirmed by the inability of endogenous lipid vesicle to induce comet tail formation and motility. Lipid vesicle motility in Xenopus extracts is mediated by a Cdc42-dependant actin polymerization process (Ma et al., 1998a,b). In our experiments, TcdB treatment abolished the GTP $\gamma$ S-induced vesicle motility, as previously reported (Moreau and Way, 1998). However, bacterial motility was not affected, suggesting that $\mathrm{Cdc} 42$, and probably the other GTPases, are not involved in IcsA-mediated actin polymerization process. This leads to the question of how Shigella induces actin polymerization and promotes bacterial motility within infected cells. Recruitement of specific cytoskeletal effector proteins by IcsA is probably sufficient to perform these functions. Neural-Wiskott Aldrich Syndrome Protein (N-WASP), a cellular ligand of IcsA, is crucial for bacterial motility (Suzuki et al., 1998) and is involved in the nucleation of actin filaments (C. Egile et al., unpublished). Interaction of N-WASP with GTP-Cdc42Hs is assumed to activate N-WASP, allowing actin polymerization and formation of cellular filopodia (Miki et al., 1998). However, our data suggest that Cdc42 is not required for Shigella motility. Recent evidence indicates that IcsA interaction with N-WASP is sufficient to activate N-WASP and to bypass the Cdc42Hs requirement (C. Egile et al., unpublished).

Rho GTPase-independent actin polymerization processes have been recently described during interaction between bacterial pathogens and host cell. Listeria is able to spread inside cells by an actin-based motility similar to Shigella (Cossart, 1997). Recent work indicates Rac1 association in Listeria comets but no functional relevance of this recruitment has been documented (David et al., 1998). However, several evidence suggest that Listeria actin polymerization process can also bypass Rho GTPases signaling. Treatment of Xenopus extracts with $\mathrm{C} 3$ exotoxin or TcdB has no effect on Listeria motility (Marchand et al., 1995; Moreau and Way, 1998) and $\mathrm{PtK}_{2}$ cells treated with TcdB toxin were still able to promote Listeria actin-based motility (F. Ebel et al., unpublished). Thus, both intracellular bacteria can bypass the Rho GTPases control and induce cytoskeletal rearrangements by direct interaction with effector proteins involved in cytoskeletal dynamics, such as Arp $2 / 3$ and N-WASP. Actin polymerization during interaction between host cell surface and enteropathogenic $E$. coli (EPEC) and Shiga toxin producing E. coli (STEC) has also been shown to be Rho GTPases-independent. These extracellular bacteria induce actin filaments polymerization and the formation of cellular extension, called pedestal, on which lies the bacterium. In some instance, pedestal can evolve in pseudopod and allow bacterial translational motility on the surface of infected cell (Sanger et al., 1996). Two recent reports suggest that of Rho GTPases inactivation by TcdB abolished cellular actin cytoskeleton but not STEC and EPEC pedestal formation (Ebel et al., 1998; Ben-Ami et al., 1998). Pedestal formation is mediated by the translocation and insertion in host cell membrane of a bacterial product, the EPEC Tir protein
(Kenny et al., 1997), and its STEC homolog EspE (Deibel et al., 1998). The cytoplasmic Tir portion is probably involved in the actin polymerization leading to pedestal formation. It may share similarities with IcsA- and ActA-mediated actin polymerization mechanisms due to its subcellular localization. The lack of involvement of Rho GTPases in both cases further emphasizes the similarities between mechanism of actin polymerization during actin comet and pedestal formation.

Although interfering with the regulation of the host cell actin cytoskeleton appears to be a common theme among a variety of bacterial pathogens, these results have clearly illustrated a diversity of molecular strategies used by pathogens. It appears that Shigella manipulates the epithelial cell cytoskeleton both by Rho GTPase-dependent process during entry and Rhoindependent mechanism during motility. The temporal regulation of cytoskeletal processes during entry and during intracellular spread are very different, supporting the idea that these two events are controlled by different mechanisms. Bacterial uptake is fast and transient and therefore requires strict and fine tuning, likely mediated by the Rho GTPases. In contrast, actin-based motility should be constitutive to allow cytoplasmic colonization and cell to cell spread. A direct recruitment of a regulator or effector of actin polymerization, downstream of the Rho signalling pathway, would fulfill these requirements and bypass the strict cytoskeletal regulation imposed by Rho proteins. These two paradigms of Rho GTPases-dependent and -independent cytoskeletal regulation are likely to bring novel insights into the physiological pathways by which cells regulate their cytoskeleton.

We thank Raymond Hellio for excellent confocal microscopy assistance. We thank Christoph von Eichel-Streiber for providing TcdB-10463 toxin, Frank Ebel for communicating information prior to publication, Thomas Adam for helpful comments and Dana Philpott for critical reading of the manuscript. This work was supported in parts by grants from the Ministère de l'Education Nationale, de la Recherche et de la Technologie (to P.J.S.), Ligue contre le cancer and the ARC fondations (to M.-F.C.). C. E. is recipient of fellowships from Fondation Louis Jeantet de Medecine and the Caisse National d'Assurance Maladie (CANAM). The confocal microscope was purchased with a donation from Marcel and Liliane Pollack.

\section{REFERENCES}

Adam, T., Arpin, M., Prévost, M. C., Gounon, P. and Sansonetti, P. J. (1995). Cytoskeletal rearrangements and the functional role of T-plastin during entry of Shigella flexneri into HeLa cells.J. Cell Biol. 129, 367-381.

Adam, T., Giry, M., Boquet, P. and Sansonetti, P. (1996). Rho-dependent membrane folding causes Shigella entry into epithelial cells. EMBO J. 15, 3315-3321.

Bar-Sagi, D. and Ferasmico, J. R. (1986). Induction of membrane ruffling and fluid-phase pinocytosis in quiescent fibroblasts by ras proteins. Science 233, 1061-1068.

Ben-Ami, G., Ozeri, V., Hanski, E., Hofmann, F., Aktories, K., Hahn, K. M., Bokoch, G. M. and Roenshine, I. (1998). Agents that inhibit Rho, Rac and $\mathrm{Cdc} 42$ do not block formation of actin pedestals in HeLa cells infected with enteropathogenic Escherichia coli. Infect. Immun. 66, 1755-1758.

Bernardini, M. L., Mounier, J., d'Hauteville, H., Coquis-Rondon, M. and Sansonetti, P. J. (1989). Identification of icsA, a plasmid locus of Shigella flexneri that governs bacterial intra and intercellular spread through interaction with F-actin. Proc. Nat. Acad. Sci. USA 86, 3867-3871.

Caron, E. and Hall, A. (1998). Identification of two distinct mechanisms of phagocytosis controlled by different Rho GTPases. Science 282, 1717-1721. Chen, L.-M., Hobbie, S. and Galán, J. E. (1996). Requirement of CDC42 
for Salmonella-induced cytoskeletal and nuclear responses. Science $\mathbf{2 7 4}$, 2115-2118.

Clerc, P. and Sansonetti, P. J. (1987). Entry of Shigella flexneri into HeLa cells: evidence for directed phagocytosis involving actin polymerization and myosin accumulation. Infect. Immun 55, 2681-2688.

Cossart, P. (1997). Subversion of the mammalian cell cytoskeleton by invasive bacteria. J. Clin Invest. 99, 2307-2311.

David, V., Gouin, E., Troys, M. V., Grogan, A., Segal, A. W., Ampe, C. and Cossart, P. (1998). Identification of cofilin, coronin, rac and capZ in actin tails using a Listeria affinity approach. J. Cell Sci. 111, 2877-2884.

Deibel, C., Kramer, S., Chakraborty, T. and Ebel, F. (1998). EspE, a novel secreted protein of attaching and effacing bacteria, is directly translocated into infected host cells, where it appears as a tyrosine-phosphorylated 90 kDa protein. Mol. Microbiol. 28, 463-474.

Dumenil, G., Olivo, J. C., Pellegrini, S., Fellous, M., Sansonetti, P. J. and Nhieu, G. T. (1998). Interferon alpha inhibits a Src-mediated pathway necessary for Shigella-induced cytoskeletal rearrangements in epithelial cells. J. Cell Biol. 143, 1003-1012.

Dutartre, H., Davoust, J., Gorvel, J. P. and Chavrier, P. (1996). Cytokinesis arrest and redistribution of actin-cytoskeleton regulatory components in cells expressing the Rho GTPase CDC42Hs. J. Cell Sci. 109, 367-377.

Ebel, F., von Eichel-Streiber, C., Rohde, M. and Chakraborty, T. (1998). Small GTP-binding proteins of the Rho- and Ras-subfamilies are not involved in the actin rearrangements induced by attaching and effacing Escherichia coli. FEBS Lett. 163, 107-112.

Finlay, B. B. and Ruschkowski (1991). Cytoskeletal rearrangements accompanying Salmonella entry into epithelial cells. J. Cell Sci. 99, 283296.

Finlay, B. and Cossart, P. (1997). Exploitation of mammalian host cell functions by bacterial pathogens. Science 276, 718-725.

Gauthier-Rouvière, C., Vignal, E., Meriane, M., Roux, P., Montcourier, P. and Fort, P. (1998). RhoG GTPase controls a pathway that independently activates Rac1 and Cdc42Hs. Mol. Biol. Cell 9, 1379-1394.

Goldberg, M. B. and Theriot, A. J. (1995). Shigella flexneri surface protein IcsA is sufficient to direct actin-based motility. Proc. Nat. Acad. Sci. USA 92, 6572-6576.

Hall, A. (1998). Rho GTPases and the actin cytoskeleton. Science 279, 509514.

Hardt, W. D., Chen, L.-M., Schuebel, K. E., Bustelo, X. R. and Galan, J. E. (1998). S.typhimurium encodes an activator of Rho GTPases that induces membrane ruffling and nuclear responses in host cells. Cell 93, 815-826.

Hartwig, J. H., Bokoch, G. M., Carpenter, C. L., Janmey, P. A., Taylor, L. A., Toker, A. and Stossel, T. P. (1995). Thrombin receptor ligation and activated Rac uncap actin filament barbed ends through phophoinositide synthesis in permabilized human platelets. Cell 82, 643-653.

Jones, B. D., Paterson, H. F., Hall, A. and Falkow, S. (1993). Salmonella typhimurium induces membrane ruffling by a growth factor-receptorindependent mechanism. Proc. Nat. Acad. Sci. USA 21, 10390-10394.

Kenny, B., DeVinney, R., Stein, M., Reinscheid, D. J., Frey, E. A. and Finlay, B. (1997). Enteropathogenic E.coli transfers its receptor for intimate adherence into mammalian cells. Cell 91, 511-520.

Kocks, C., Marchand, J. B., Gouin, E., d'Hauteville, H., Sansonetti, P. J., Carlier, M. F. and Cossart, P. (1995). The unrelated surface proteins ActA of Listeria monocytogenes and IcsA of Shigella flexneri are sufficient to confer actin-based motility to L. innocua and E. coli respectively. Mol. Microbiol. 18, 413-423.

Kozma, R., Ahmed, S., Best, A. and Lim, L. (1995). The Ras-related protein $\mathrm{Cdcd} 42 \mathrm{Hs}$ and bradykinin promote formation of peripheral actin microspikes and filopodia in Swiss 3 T3 fibroblasts. Mol. Cell Biol. 15, 19421952.

Labrec, E. H., Schneider, H., Magnani, T. J. and Formal, S. B. (1964). Epithelial cell penetration as an essential step in the pathogenesis of bacillary dysentery.Infect. Immun. 88, 1503-1518.

Ma, L., Cantley, L. C., Janmey, P. A. and Kirschner, M. W. (1998a).
Corequirement of specific phosphoinositides and small GTP-binding protein Cdc42 in inducing actin assembly in Xenopus cells extracts. J. Cell Biol. 140, 1125-1136.

Ma, L., Rohatgi, R. and Kirschner, M. W. (1998b). The Arp2/3 complex mediates actin polymerization induced by the small GTP-binding protein Cdc42. Proc. Nat. Acad. Sci. USA 95, 15362-15367.

Machesky, L. M. and Hall, A. (1997). Role of actin polymerization and adhesion to extracellular matrix in Rac-and Rho-induced cytoskeletal reorganization. J. Cell Biol. 138, 913-926.

Marchand, J. B., Moreau, P., Paoletti, A., Cossart, P., Carlier, M. F. and Pantaloni, D. (1995). Actin-based movement of Listeria monocytogenes: actin assembly results from the local maintenance of uncapped filament barbed ends at the bacterium surface. J. Cell Biol. 130, 331-343.

Massol, P., Montcourrier, P., Guillemot, J. C. and Chavrier, P. (1998). Fc receptor-mediated phagocytosis requires CDC42 and Rac1. EMBO J. 17, 6219-6229.

Ménard, R., Prévost, M. C., Gounon, P., Sansonetti, P. and Dehio, C. (1996a). The secreted Ipa complex of Shigella flexneri promotes entry into mammalian cells. Proc. Nat. Acad. Sci. USA 93, 1254-1258.

Ménard, R., Dehio, C. and Sansonetti, P. J. (1996b). Bacterial entry into epithelial cells: the paradigm of Shigella. Trends Microbiol.4, 220-226.

Miki, H., Sasaki, T., Takai, Y. and Takenawa, T. (1998). Induction of filopodium formation by a WASP-related actin-depolymerizing protein NWASP. Nature 391, 93-96.

Moreau, V. and Way, M. (1998). Cdc42 is required for membrane dependent actin polymerization in vitro. FEBS Lett. 427, 353-356.

Nobes, C. D. and Hall., A. (1995). Rho, Rac, and CDC42 GTPases regulate the assembly of multimolecular focal complexes associated with actin stress fibers, lamellipodia, and filopodia. Cell 81, 53-62.

Ridley, A. J. and Hall, A. (1992). The small GTP-binding protein Rho regulates the assembly of focal adhesions and stress fibers in response to growth factors. Cell 70, 389-399.

Ridley, A. J., Paterson, H. F., Johnston, C. L., Diekmann, D. and Hall, A. (1992). The small GTP-binding protein Rac regulates growth factor-induced membrane ruffling. Cell 70, 401-410.

Sanger, M. J., Chang, R., Ashton, F., Kaper, J. B. and Sanger, J. W. (1996). Novel form of actin-based motility transports bacteria on the surfaces of infected cells. Cell Motil. Cytoskel. 34, 279-287.

Sansonetti, P. J., Mounier, J., Prévost, M. C. and Mège, R. M. (1994). Cadherin expression is required for the spread of Shigella flexneri between epithelial cells. Cell 76, 829-839.

Suzuki, T., Miki, H., Takenawa, T. and Sasakawa, C. (1998). Neural Wiskott-Aldrich Syndrome Protein is implicated in the actin-based motility of Shigella flexneri. EMBO J. 17, 2767-2776.

Theriot, J. A., Mitchison, T. J., Tilney, L. G. and Portnoy, D. A. (1992). The rate of actin-based motility of intracellular Listeria monocytogenes equals the rate of actin polymerization. Nature 357, 257-260.

Tran Van Nhieu, G., Ben-Ze'ev, A. and Sansonetti, P. J. (1997). Modulation of bacterial entry into epithelial cells by association between vinculin and Shigella IpaA invasin. EMBO J. 16, 2717-2729.

Van Aelst, L. and D'Souza-Schorey, C. (1997). Rho GTPases and signaling networks. Genes Dev. 11, 2295-2322.

von Eichel-Streiber, C., Harperath, U., Bosse, D. and Hadding, U. (1987). Purification of two high molecular weight toxins of Clostridium difficile which are antigenically related. Microb. Pathog. 2, 307-318.

Watarai, M., Kamata, Y., Kozaki, S. and Sasakawa, C. (1997). Rho, a small GTP-binding protein is essentiel for Shigella invasion of epithelial cells. $J$. Exp. Med. 185, 281-292.

Zigmond, S. H., Joyce, M., Borleis, J., Bokoch, G. M. and Devreotes, P. N. (1997). Regulation of actin polymerization in cell-free systems by GTP $\gamma \mathrm{S}$ and Cdc42. J. Cell Biol. 138, 363-374.

Zigmond, S. H., Joyce, M., Yang, C., Brown, K., Huang, M. and Pring, M. (1998). Mechanism of Cdc42-induced actin polymerization in neutrophil extracts. J. Cell Biol. 142, 1001-1012. 